\title{
Cilostazol Activates Function of Bone Marrow-Derived Endothelial Progenitor Cell for Re-endothelialization in a Carotid Balloon Injury Model
}

\author{
Rie Kawabe-Yako ${ }^{1,2}$, Masaaki $\mathrm{li}^{3,1 *}$, Osamu Masuo ${ }^{2}$, Takayuki Asahara ${ }^{1,4 *}$, Toru Itakura ${ }^{2}$ \\ 1 Group of Vascular Regeneration Research, Institute of Biomedical Research and Innovation, RIKEN Center for Developmental Biology, Kobe, Japan, 2 Department of \\ Neurosurgery, Wakayama Medical University, Wakayama, Japan, 3 Group of Translational Stem Cell Research, Department of Pharmacology, Osaka Medical College, Osaka, \\ Japan, 4 Department of Regenerative Medicine Science, Tokai University School of Medicine Kanagawa, Japan
}

\begin{abstract}
Background: Cilostazol(CLZ) has been used as a vasodilating anti-platelet drug clinically and demonstrated to inhibit proliferation of smooth muscle cells and effect on endothelial cells. However, the effect of CLZ on re-endothelialization including bone marrow (BM)-derived endothelial progenitor cell (EPC) contribution is unclear. We have investigated the hypothesis that CLZ might accelerate re-endothelialization with EPCs.

Methodology/Principal Findings: Balloon carotid denudation was performed in male Sprague-Dawley rats. CLZ group was given CLZ mixed feed from 2 weeks before carotid injury. Control group was fed normal diet. CLZ accelerated reendothelialization at 2 weeks after surgery and resulted in a significant reduction of neointima formation 4 weeks after surgery compared with that in control group. CLZ also increased the number of circulating EPCs throughout the time course. We examined the contribution of BM-derived EPCs to re-endothelialization by BM transplantation from Tie2/lacZ mice to nude rats. The number of Tie2-regulated X-gal positive cells on injured arterial luminal surface was increased at 2 weeks after surgery in CLZ group compared with that in control group. In vitro, CLZ enhanced proliferation, adhesion and migration activity, and differentiation with mRNA upregulation of adhesion molecule integrin $\alpha v \beta 3$, chemokine receptor CXCR4 and growth factor VEGF assessed by real-time RT-PCR in rat BM-derived cultured EPCs. In addition, CLZ markedly increased the expression of SDF-1 $\alpha$ that is a ligand of CXCR4 receptor in EPCs, in the media following vascular injury.

Conclusions/Significance: CLZ promotes EPC mobilization from BM and EPC recruitment to sites of arterial injury, and thereby inhibited neointima formation with acceleration of re-endothelialization with EPCs as well as pre-existing endothelial cells in a rat carotid balloon injury model. CLZ could be not only an anti-platelet agent but also a promising tool for endothelial regeneration, which is a key event for preventing atherosclerosis or restenosis after vascular intervention.
\end{abstract}

Citation: Kawabe-Yako R, Li M, Masuo O, Asahara T, Itakura T (2011) Cilostazol Activates Function of Bone Marrow-Derived Endothelial Progenitor Cell for Reendothelialization in a Carotid Balloon Injury Model. PLoS ONE 6(9): e24646. doi:10.1371/journal.pone.0024646

Editor: Gian Paolo Fadini, University of Padova, Italy

Received February 11, 2011; Accepted August 16, 2011; Published September 12, 2011

Copyright: (c) 2011 Kawabe-Yako et al. This is an open-access article distributed under the terms of the Creative Commons Attribution License, which permits unrestricted use, distribution, and reproduction in any medium, provided the original author and source are credited.

Funding: This work was supported by research funding from the Ministry of Health, Labor and Welfare Organization in Japan, and the Foundation of Biomedical Research and Innovation of Kobe. The funders had no role in study design, data collection and analysis, decision to publish, or preparation of the manuscript.

Competing Interests: The authors have declared that no competing interests exist.

*E-mail: asa777@is.icc.u-tokai.ac.jp (TA); masaii@art.osaka-med.ac.jp (MI)

\section{Introduction}

Re-endothelialization inhibits neointimal thickening, thereby suppressing development of the substrate for lipid deposition and macrophage accumulation that is believed to induce the formation of atherosclerotic lesions and may contribute to restenosis. Drugeluting stents (DESs) have significantly reduced the rate of restenosis; however, DESs also appear to delay re-endothelialization [1]. This delay results in excessive rates of thrombosis, which could increase the occurrence of acute coronary syndromes. Endothelial cell loss from arterial wall resulting from mechanical removal (hemodynamic forces, PTCA, stenting) or cell apoptosis, might induce a cascade of events giving rise to vascular inflammation, smooth muscle cells proliferation and activation of thrombosis and lead to neointimal hyperplasia and vascular remodeling, eventually inducing restenosis, that is key features of atherosclerosis development, progression and complication. Thrombosis occurs as a consequence of the exposure of thrombogenic surfaces, both stent and denuded vascular wall, to blood stream. Therefore, acceleration of re-endothelialization is a very useful not only to repair endogenously injured vessels, but also to reduce neointimal formation and prevent intrastent restenosis and atherosclerosis development.

Endogenous re-endothelialization is driven not only by migration and proliferation of resident endothelial cells (ECs) adjacent to sites of injury, but also with the activity of endothelial progenitor cells (EPCs). Studies performed in our laboratory and others demonstrated that both exogenously infused EPCs and EPCs derived from bone marrow (BM) which can be mobilized to circulation by ischemia [2,3], physical training [4], and the administration of statins $[5,6]$, estrogen $[7,8]$, and a variety of cytokines $[9,10,11]$, recruited to sites of arterial injury, where they promote re-endothelialization directly by the differentiation into mature endothelial cells and also indirectly by stimulating resident ECs and enhancing above process via EPG-released cytokines. 
Cilostazol (CLZ) is a selective inhibitor of phosphodiesterase 3 (PDE3), and CLZ increases intracellular cAMP content and activates protein kinase A (PKA) [12], resulting in antiplatelet aggregation and peripheral vasodilatation. CLZ has therefore been used as a vasodilating anti-platelet drug for the treatment of ischemic symptoms in chronic peripheral arterial obstruction or intermittent claudication and for preventing recurrence of cerebral infarction [13,14]. CLZ also inhibits vascular smooth muscle cell proliferation and has been shown to reduce neointima formation following arterial injury in animal models $[15,16,17]$. It has also been demonstrated that CLZ reduces post-procedural in-stent restenosis (ISR) after coronary artery stenting in the CREST trial $[18,19]$ and carotid artery stenting. [20] For the mechanistic insight of anti-neointimal formation, CLZ was shown to protect EGs from apoptosis induced by serum deprivation, high d-glucose, and lipopolysaccharide (LPS) [21,22] via a hepatocyte growth factor production [23] and a suppression of superoxide production induced by remnant lipoprotein particles [24]. Moreover, it was reported that CLZ attenuated the expression of vascular cell adhesion molecule-1 (VCAM-1) [25] and monocyte chemoattractant protein-1 (MCP-1) [26] and intercellular adhesion molecule (ICAM-1) and P-selectin [27], as a result, CLZ prevented monocyte or neutrophil adhesion to endothelial cells. CLZ has pleiotropic effects on vascular remodeling following injury as described above, however, the effect of CLZ on re-endothelialization, specifically, including EPC contribution has not been investigated. We therefore tested the hypothesis that CLZ might accelerate re-endothelialization in a rat carotid balloon injury model, and analyzed the pathophysiological functions of CLZ in EPC biology.

\section{Results}

\section{Cilostazol Accelerates Re-endothelialization in Injured Artery}

To evaluate the effect of CLZ on re-endothelialization, the carotid endothelial recovery following balloon denudation was assessed by Evans Blue staining. CLZ treatment accelerated reendothelialization in the balloon-injured arterial segments. (Figure 1A) At 2 weeks, the re-endothelialized area in the CLZtreated rats $(n=7)$ was $80.4 \pm 5.8 \%$ of the total denuded area. In contrast, the re-endotheliialized area was limited to $49.6 \pm 4.9 \%$ of the total denuded area in the control group $(\mathrm{n}=7)(P<0.001)$. At 4 weeks, re-endothelialized area in both control group and CLZ group were around $90 \%$ of the denuded area $(91.6 \pm 3.4 \%$ vs. $91.4 \pm 3.7 \%$, NS), suggesting that although re-endothelialization was almost completed at 4 weeks in both groups CLZ accelerated re-endothelialization in subacute phase which is critical timing for preventing neointimal development following arterial injury. (Figure 1B).

\section{Cilostazol Inhibits Neointima Formation following Arterial Injury}

The effect of CLZ on neointimal thickening was also examined at 2 and 4 weeks after carotid injury. (Figure 2A) In control rats $(\mathrm{n}=13)$, intimal area/medial area $(\mathrm{I} / \mathrm{M})$ ratios increased markedly at 2 weeks $(1.38 \pm 0.10)$ and 4 weeks $(2.10 \pm 0.17)$. In contrast, I/M ratios of animals treated with CLZ $(\mathrm{n}=13)$ were $0.66 \pm 0.11$ at 2 weeks and $1.21 \pm 0.33$ at 4 weeks $(P<0.05$ vs. control animals). (Figure 2B) CLZ exhibited statistically significant reduction of

A
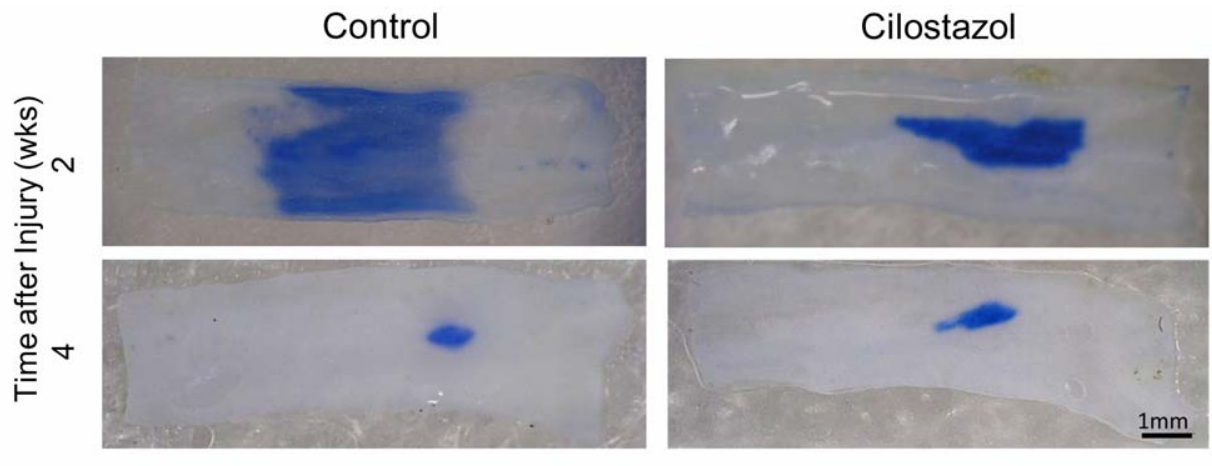

B

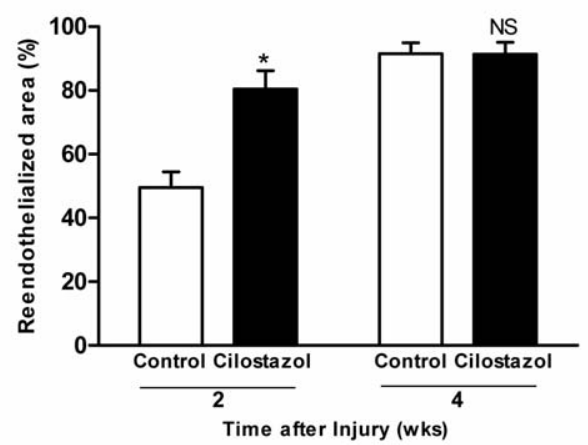

Figure 1. Cilostazol accelerates reendothelialization in injured carotid artery. (A) Rats were given cilostazol mixed feed (Cilostazol group) or normal diet (Control group) 2 weeks prior to carotid injury until time of sacrifice. Representative photomacrographs of Evans Blue dye staining of whole-mount en-face carotid arteries at 2 and 4 weeks after carotid balloon denudation. White area represent injured arterial wall covered with regenerated endothelium, and blue area represent injured arterial wall without endothelium. (B) Quantification of reendothelialized area was expressed as mean \pm SEM. ${ }^{*}, P<0.001$ and NS vs. Control ( $n=7$ in each group).

doi:10.1371/journal.pone.0024646.g001 
A

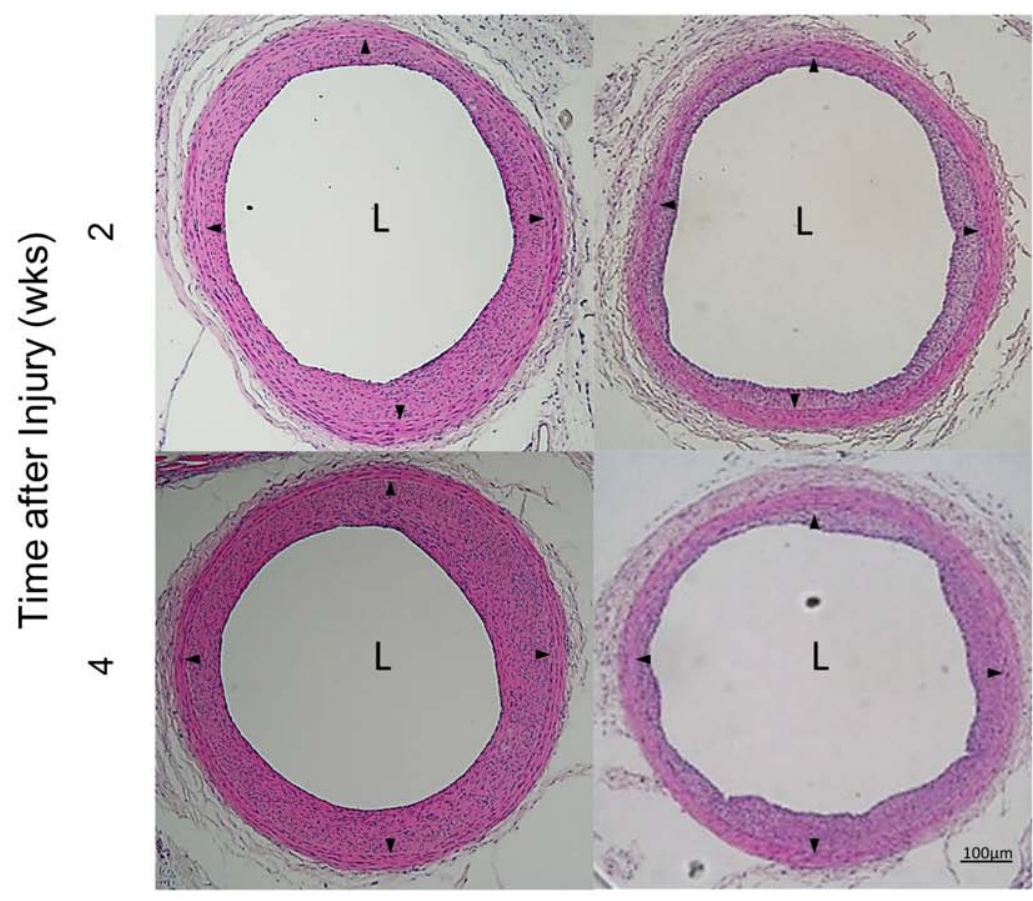

B

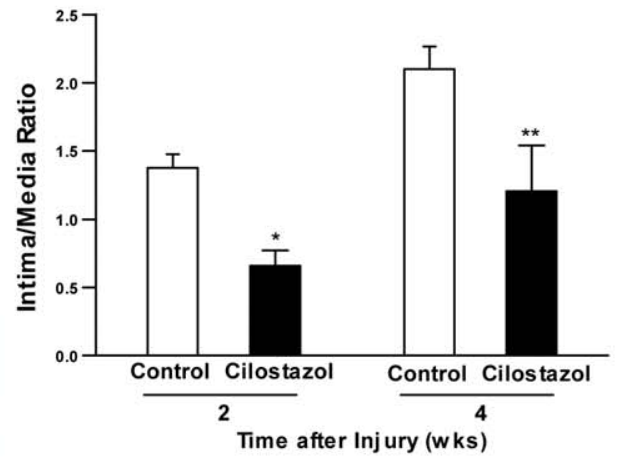

Figure 2. Cilostazol reduces neointima formation in injured carotid artery. (A) Rats were fed with Cilostazol containing diet (Cilostazol group) or normal diet (control group) from 2 weeks prior to carotid injury until time of sacrifice. Representative photomicrographs of H.E. stained histological cross sections in Cilostazol group $(n=5)$ vs. Control group $(n=6)$ at 2 and 4weeks after carotid injury. Black arrows indicate internal elastic lamina. (B) Intima/Media ratio was expressed as mean \pm SEM. ${ }^{*}, P<0.05$ and ${ }^{* *} P<0.01$ vs. control. doi:10.1371/journal.pone.0024646.g002

neointimal thickening as well as acceleration of re-endothelialization compared with controls.

\section{Cilostazol Increases Number of Circulating EPCs}

To assess the number of circulating EPCs in peripheral blood, EPC culture assay was performed by double staining of cultured EPCs with DiI-acLDL and BS1-lectin. (Figure 3-A and 3-B) The number of circulating EPCs exhibited significant two-fold increase in CLZ group compared to control group (239 25 vs. $113 \pm 14 /$ $\mathrm{mm}^{2}, \quad P<0.001, \mathrm{n}=8$ ) before surgery, and the significant difference of 2.3-fold increase between CLZ group and control

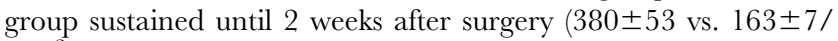
$\left.\mathrm{mm}^{2}, P<0.001, \mathrm{n}=5\right)$. At 4 weeks after surgery, the number of circulating EPCs in both groups decreased to similar level $(98 \pm 16$ vs. $70 \pm 10, \mathrm{NS}, \mathrm{n}=8$ ). (Figure $3-\mathrm{C}$ ) Since the number of EPCs assessed by EPC culture assay correlates with those assessed by FACS analysis with markers for Sca-1/Flk-1 in mouse peripheral blood-derived mononuclear cells $[7,8]$, these findings suggest that CLZ has an effect of EPC mobilization from BM and CLZ further boosts the mobilization in subacute phase following vascular injury.

\section{Characterization of EPCs}

EPCs derived from peripheral blood were cultured in EPC differentiation medium for 4 days and characterized by immunofluorescent staining. Most of the EPCs expressed both several leukocyte antigens (CD14, CD45, CD34) and endothelial antigens (CD31, fetal liver kinase 1 (Flk-1), endothelial nitric oxide synthase (eNOS), von Willebrand factor (vWF)). (Figure 3-D).

\section{Cilostazol Enhances BM-derived EPC Contribution to Re- endothelialization}

To assess the contribution of BM-derived EPCs to accelerated re-endothelialization, BM from Tie2/lacZ mice was transplanted to nude rats, and carotid arteries were harvested from Tie2/LacZ BM transplanted nude rats 2 weeks after balloon injury. In this model, BM-derived EPCs originated from donor transgenic mouse are detected by $\beta$-galactosidase expression by LacZ gene which is regulated by endothelial specific Tie 2 promotor. The $\beta$-galactosidase expression was identified by $\mathrm{X}$-gal chemical staining or by immunochemical staining in tissue samples. The number of X-galpositive cells on luminal surface was significantly greater in CLZ group $(\mathrm{n}=5)$ cells $/ \mathrm{mm}^{2}$ than that in control group $(\mathrm{n}=5)(48 \pm 4$ vs. $31 \pm 2$ cells $/ \mathrm{mm}^{2}, P<0.01$ ). (Figure $4 \mathrm{~A}$ and $4 \mathrm{~B}$ ) In addition, BM-derived Tie2/LacZ-positive EPGs were further identified by double-fluorescence immunostaining for $\beta$-galactosidase and the endothelium-specific marker isolectin B4 with cross sections at 2 weeks after carotid injury. In cross sections of carotid arteries from control group, only a few $\beta$-gal-positive and isolectin B4 doublepositive cells were observed on the luminal surface. In contrast, numerous double-positive cells were observed on the re-endothelialized luminal surface in carotid arteries from CLZ-treated animals. (Figure 4C) These findings thus suggest that accelerated re-endothelialization achieved with CLZ involves enhanced EPC recruitment to the regenerated neoendothelium.

\section{Cilostazol Increases EPC Functions In Vitro}

To explore active mechanism of CLZ on rat EPGs, we performed a series of in vitro studies. The proliferation activity of EPCs pre-incubated with CLZ was significantly increased 
A
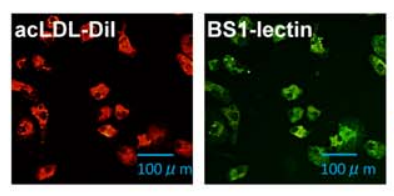

B

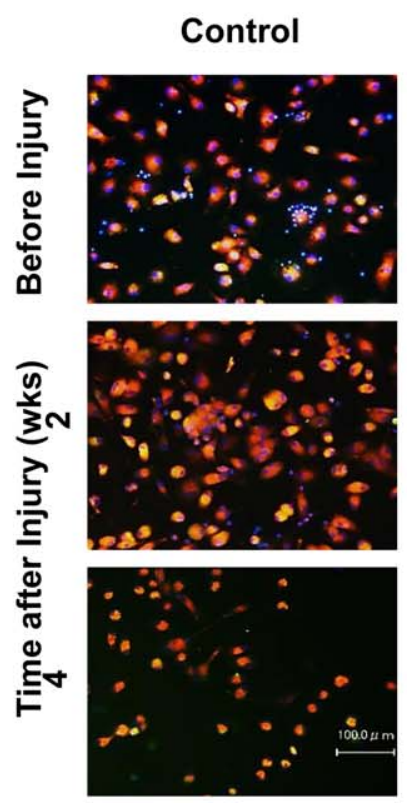

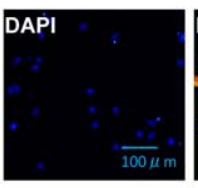

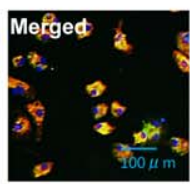

C

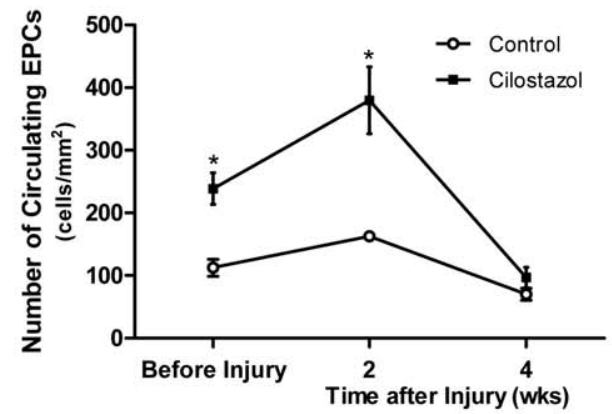

D
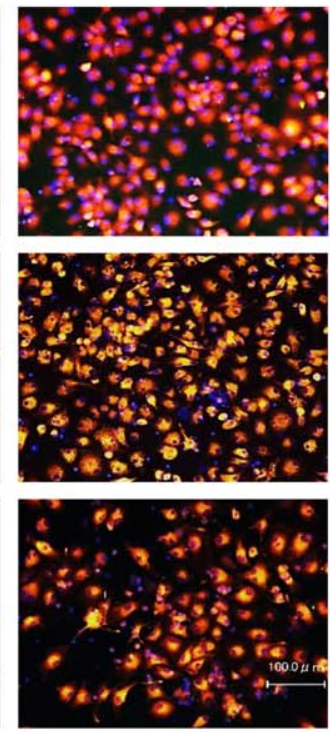

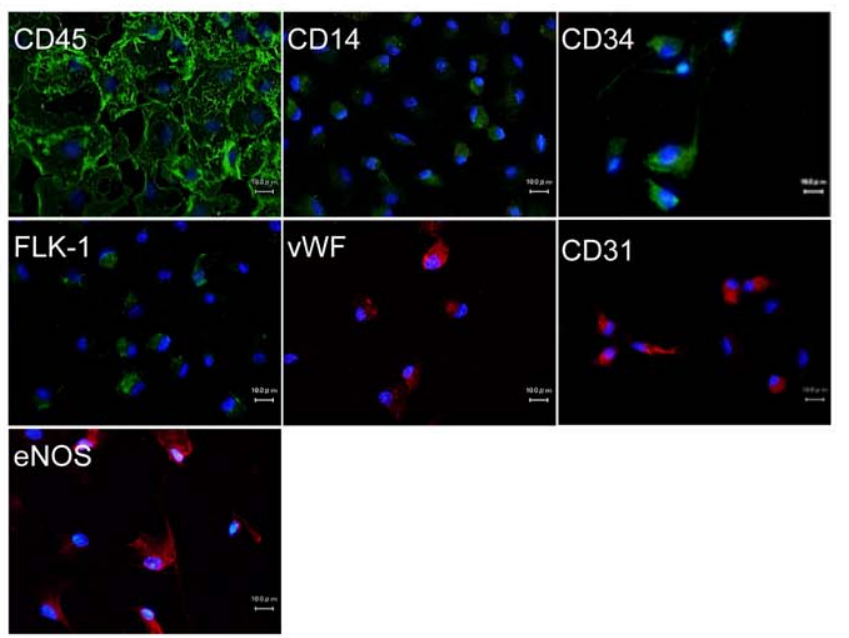

Figure 3. Representative fluorescent images of rat EPC culture assay. (A) Mononuclear cells isolated from $500 \mu$ l of peripheral blood were cultured in EPC differentiation medium for 4days, and stained with acLDL/Dil (red), FITC-conjugated BS-1 lectin (green) and DAPI (blue). (B) Cilostazol increases number of circulating EPCs. Rats were fed with Cilostazol containing diet (Cilostazol group) or normal diet (Control group) from 2 weeks prior to carotid injury until time of sacrifice. Representative microphotographs of triple staining with Dil-acLDL and FITC conjugated BS-1 lectin and DAPI of circulating EPCs cultured for 4days after isolation from peripherial blood just before and at 2 and 4 weeks after balloon injury. (C) Quantification of circulating EPCs detected by Dil-acLDL/FITC-BS-1 lectin double positive cells in control group $(n=8)$ and the cilostazol-treated group $(n=7) *, P<0.001$ vs. Control. (D) Characterization of rat peripheral blood-derived EPCs was performed. After 4 days in culture, cells were stained by immunofluorescence with antibodies against CD14, CD45, CD34, CD31, Flk-1, eNOS and vWF.

doi:10.1371/journal.pone.0024646.g003

compared with that of vehicle-treated EPGs in a dose dependent manner. (Optical density at $450 \mathrm{~nm}$ wavelength: Vehicle $0.143 \pm 0.002$ vs. $1 \mu \mathrm{M} \quad 0.152 \pm 0.002, P<0.05 ; 3 \mu \mathrm{M} \quad 0.152 \pm$ $0.002, P<0.05 ; 10 \mu \mathrm{M} 0.157 \pm 0.001, P<0.01 ; 30 \mu \mathrm{M} \quad 0.163 \pm$ $0.001, P<0.001)$. (Figure 5A).

Next, cultured EPCs were incubated with CLZ at the indicated concentrations for 3 hours for assessment of adhesion activity. The adhesion activity of EPCs pre-incubated with CLZ was significantly increased, and CLZ-induced adhesion activity effect was enhanced peaking at a dose of $10 \mathrm{mM}$. (Adhered cell number: Vehicle $6994 \pm 108$ vs. $1 \mu \mathrm{M}$ 8418 241 ; $3 \mu \mathrm{M} \quad 10156 \pm 237$; $10 \mu \mathrm{M} 11303 \pm 176 ; 30 \mu \mathrm{M} 9954 \pm 231$ cells/well, $P<0.001$ ). (Figure 5B).

The migration activity in response to SDF- $1 \alpha$ of EPCs preincubated with CLZ was significantly increased compared with vehicle-treated EPCs in a dose dependent manner. (Migration index: Vehicle $1.68 \pm 0.25$ vs. $1 \mu \mathrm{M} 2.23 \pm 0.16$, NS; $3 \mu \mathrm{M} 4.24 \pm 0.46$ $P<0.05 ; 10 \mu \mathrm{M} 4.68 \pm 0.67, P<0.001 ; 30 \mu \mathrm{M} 4.46 \pm 1.00, P<0.001)$ However, there was no promotional effect of CLZ on VEGF-induced EPC migration activity. (Figure $5 \mathrm{C}$ ) This finding allowed us to focus on the association of CLZ and SDF-1 $\alpha /$ CXCR4 signaling pathway rather than VEGF signaling pathway in EPC biological functions.

\section{Cilostazol Enhances EPC Differentiation and Homing- related Gene Expression}

To investigate whether CLZ has an impact on EPG differentiation, the effect of CLZ on mRNA expressions of EC lineage markers CD31 and vWF was examined by quantitative real-time RT-PCR at 2 days of growth after 3-hour CLZ treatment with the indicated concentrations. The mRNA expressions of CD31 and vWF were significantly upregulated in cultured EPGs with CLZ at doses of 3, 10, and $30 \mu \mathrm{M}$ (Figure 6A) and only $30 \mu \mathrm{M}$ (Figure 6C), respectively. We next further confirmed the protein expressions of CD31 and vWF in cultured EPCs by immunofluorescent staining. Numerous staining positive cells for CD31 (Figure 6B) and vWF (Figure 6D) were observed at 2 days of growth after 3-hour CLZ $(30 \mu \mathrm{M})$ treatment, while only a few cells stained positive for CD31 and vWF without CLZ. Thus, by evaluating the expression of 2 different EC markers, CLZ directly enhanced EPC differentiation to EG lineage in vitro.

Based on the result of EPG adhesion/proliferation activity increase by CLZ and migration activity increase in response to SDF- $1 \alpha$ but not VEGF as described above, the mRNA expression of integrin $\alpha_{\mathrm{V}}$ and integrin $\beta 3$ which are representative adhesion molecules in EPGs, CXGR4 which is a receptor for SDF-1 $\alpha$, and 
A

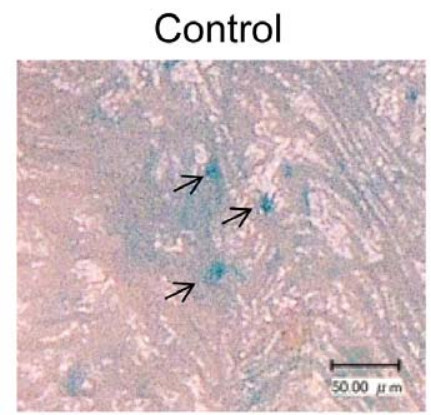

C

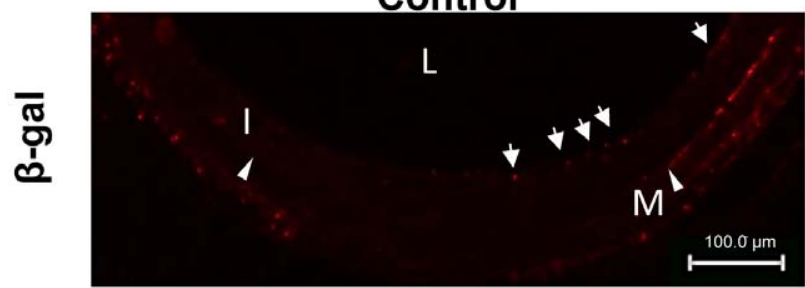

Control

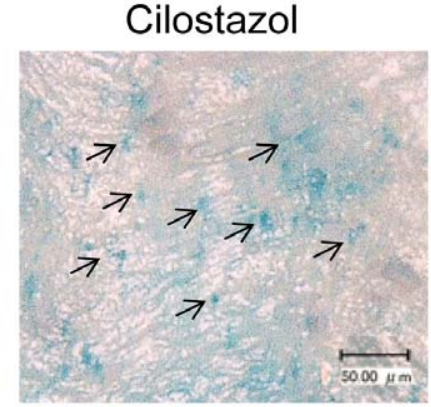

B

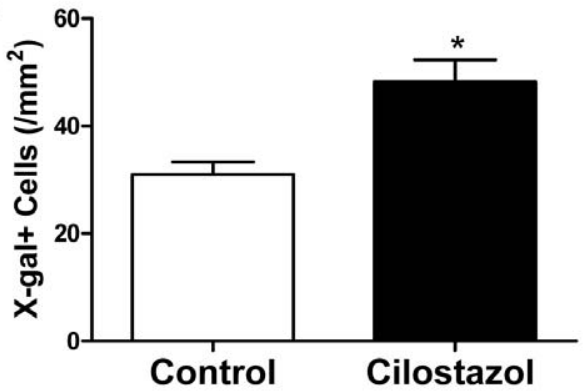

Cilostazol
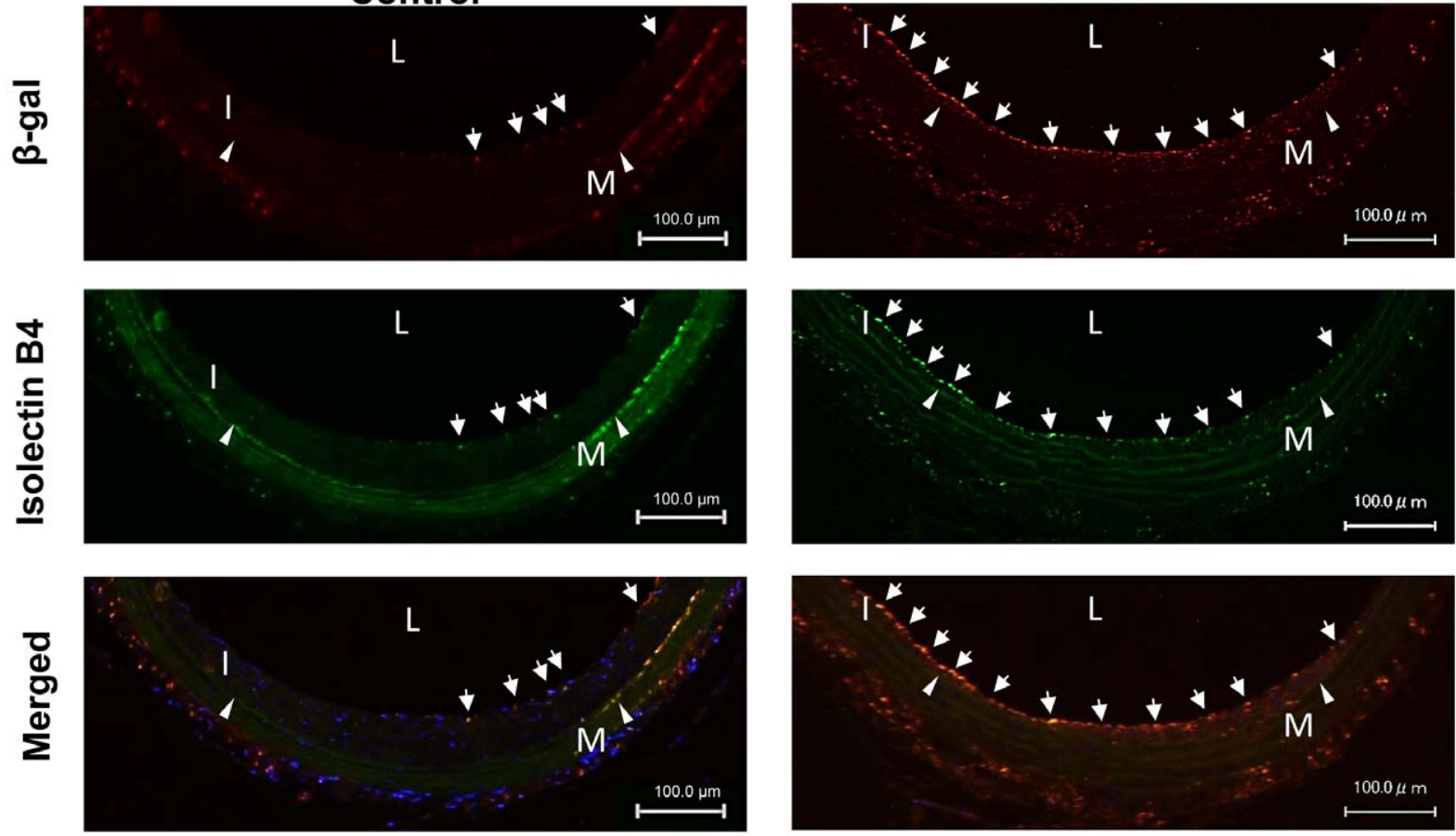

Figure 4. Cilostazol promotes bone marrow-derived EPC recruitment to denuded carotid artery. (A) Nude rats were transplanted with bone marrow of Tie2/lacZ mice and fed with Cilostazol containing diet (Cilostazol group) or normal diet (Control group) from 2 weeks prior to carotid injury until time of sacrifice. Carotid arteries were denuded 6 weeks after bone marrow transplantation and harvested 2 weeks after balloon injury. Representative photomacrographs of luminal surface of X-gal stained injured. ( $n=5$ in each group) (B) Number of X-gal-positive (blue) cells on luminal surface was counted and averaged. ${ }^{*} P<0.01$ vs. Control. (C) Representative photographs of double immunofluorescence staining for $\beta$ galactosidase ( $\beta$-gal, red) and isolectin B4 (green) with cross sections at 2 weeks after carotid injury. IEL, internal elastic lamina (Arrowheads); I, intima; $\mathrm{L}$, lumen; and $\mathrm{M}$, media. Arrows indicate $\beta$-gal and isolectin B4-double positive cells.

doi:10.1371/journal.pone.0024646.g004

VEGF which is a critical growth factor for EPC differentiation, migration, and proliferation were examined by quantitative realtime RT-PGR. EPGs were grown for 5 days and were then incubated with CLZ for 3 hours at the indicated concentrations. The mRNA expressions of integrin $\alpha_{\mathrm{V}}$ (Figure $7 \mathrm{~A}$ ) and integrin $\beta 3$ (Figure 7B) were significantly upregulated by CLZ treatment at a dose of $10 \mu \mathrm{M}$ and doses of $10 \mu \mathrm{M}$ and $30 \mu \mathrm{M}$, respectively. CLZ treatment also upregulated CXCR4 mRNA expression (Figure 7G) at any concentrations and did VEGF mRNA expression (Figure 7D) at doses of $10 \mu \mathrm{M}$ and $30 \mu \mathrm{M}$. These findings will be able to explain the reason of EPC functional activation by CLZ treatment.

\section{Cilostazol Enhances Medial Expression of SDF- $1 \alpha$ in Injured Artery}

We then examined the expression of SDF- $1 \alpha$ in injured artery one week after surgery by both quantitative real-time RT-PCR and immunofluorescent staining. The SDF- $1 \alpha$ mRNA expression was significantly upregulated in the CLZ-treated rats compared with that in control rats. (Figure 8A) Next, SDF- $1 \alpha$-positive cells were identified in injured vascular wall by double-fluorescent immunostaining for SDF- $1 \alpha$ and smooth muscle (SM) $\alpha$-actin with cross sections. Only a few/SM $\alpha$-actin double positive cells were observed in the media in control animals. In contrast, numerous double-positive cells were observed in the media in the CLZtreated animals (Figure 8B). These data suggest that CLZ enhance the expression of SDF- $1 \alpha$ in the injured artery, specifically, in the medial vascular smooth muscle cells (VSMCs). Also, the production of SDF- $1 \alpha$ from medial VSMCs might contribute to the recruitment of CXCR4 positive circulating EPCs.

\section{Discussion}

In the present study, we have demonstrated novel biological effects of CLZ on vascular remodeling following arterial injury, 
A

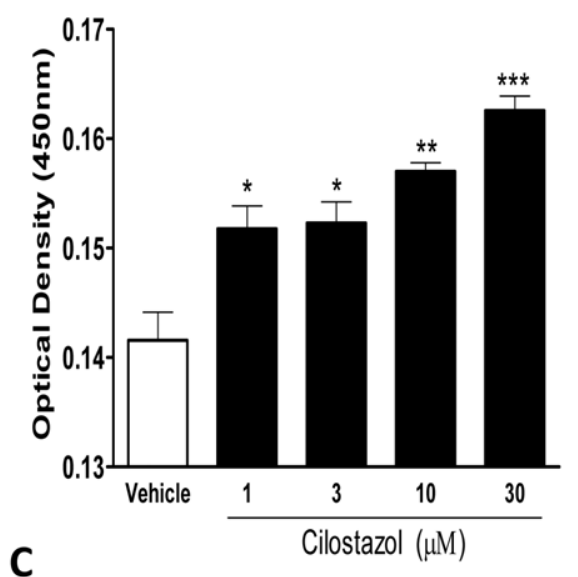

B

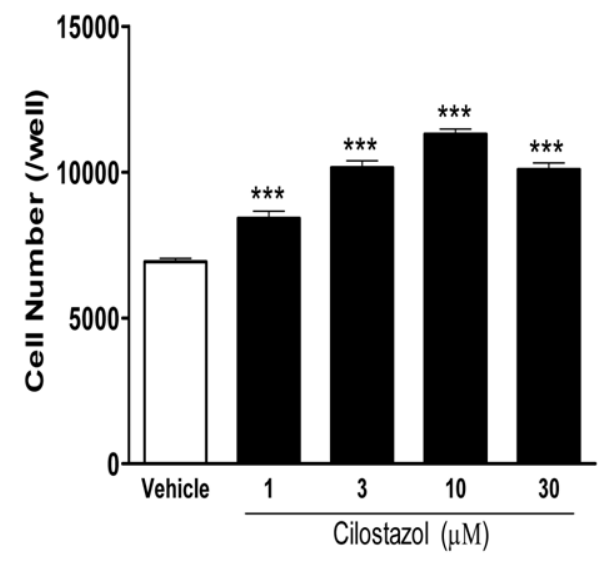

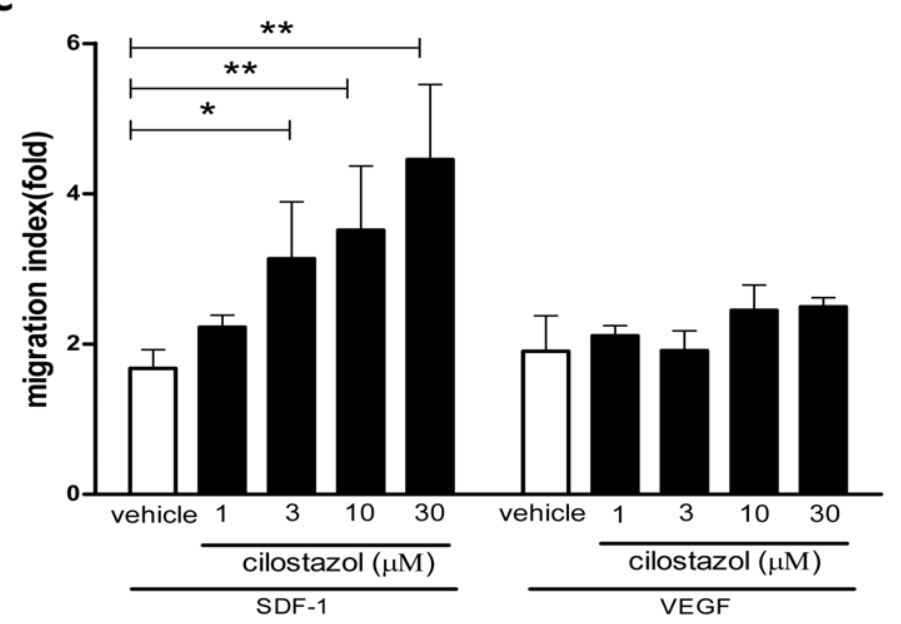

Figure 5. EPC functional assays by Cilostazol treatment. (A) Cilostazol increases EPC proliferation activity. Cultured EPCs were treated with Cilostazol at the indicated concentrations for $3 \mathrm{~h}$ and incubated for further $48 \mathrm{~h}$ and proliferation activity was examined by colorimetric assay system. ${ }^{*}, P<0.05 ;{ }^{* *}, P<0.01$; and ${ }^{* * *}, P<0.001$ vs. Vehicle. (B) Cilostazol increases EPC adhesion activity. Cultured EPCs were treated with Cilostazol at the indicated concentrations for $3 \mathrm{~h}$ and reseeded on a 96-well plate $\left(5 \times 10^{4}\right.$ cells/well) with Pronectin $\mathrm{F}$ and incubated. After one hour in culture, adherent cells were fixed and stained with DAPI. DAPI positive cells were counted in 6 different wells under fluorescent microscope (100X) and averaged. ${ }^{*}, P<0.001$ vs. Vehicle. (C) Cilostazol increases EPC migration activity. Modified Boyden's chamber assay was performed. Cultured EPCs were treated with Cilostazol at the indicated concentrations for $3 \mathrm{~h}$. Cells $\left(1 \times 10^{5}\right.$ cells) were placed in upper chamber and lower chamber was filled with medium containing SDF-1 $\alpha(100 \mathrm{ng} / \mathrm{ml})$ or VEGF $(50 \mathrm{ng} / \mathrm{ml})$ or no chemoattractant (negative control) and incubated for $16 \mathrm{~h}$. Migrated cells were counted following H.E. staining and the migration activity was expressed as a migration index calculated by dividing the number of migrated cells in the presence of SDF- $1 \alpha$ or VEGF by the number of migrated cells in the negative controls. ${ }^{*}, P<0.05$ and ${ }^{* *}, P<0.01$ vs. Vehicle. All experiments were performed in triplicate and confirmed the reproducibility.

doi:10.1371/journal.pone.0024646.g005

specifically, involving BM-derived EPC contribution to reendothelialization which is a critical response to vascular injury in terms of inhibiting neointima formation. The major findings of this study are: 1) CLZ inhibits neointima formation accelerating re-endothelialization in injured artery, 2) CLZ-inducd accelerated re-endothelialization is mediated by EPC mobilization from BM and circulating EPC recruitment to neoendothelium, 3) CLZ enhances functional properties, adhesion, migration proliferation, and differentiation upregulating adhesion molecule integrin $\alpha v \beta 3$, chemokine receptor CXCR4, and growth factor VEGF mRNA in EPCs, and 4) CLZ markedly increase the expression of SDF-1 $\alpha$, which is a ligand for its receptor CXCR4, in medial VSMCs after injury, suggesting that CLZ accelerates re-endothelialization with enhanced EPC recruitment via a SDF-1 $\alpha /$ CXCR 4 axis in injured arteries.

EPCs were classified into two major cell types according to their time-dependent appearance in culture, so-called early-outgrowth
EPCs and late-outgrowth EPCs. Early-outgrowth EPCs (eoEPCs) were obtained by culturing isolated mononuclear cells for 4-7 days and late-outgrowth EPCs (loEPCs) were appeared after 14-21 days in culture demonstrating acetylated LDL uptake and binding to Ulex lectin with expressions of CD31, CD34 (generally at low levels),VE-cadherin, Flk-1 and vWF. Unlike mature endothelial cells, eoEPCs express a monocyte marker CD14 and a panleucocyte marker CD45 [28,29,30,31]. A beneficial effect on endothelial repair after injury has been shown by eoEPCs in previous studies [32,33,34], and cultured EPCs we used in this study were also characterized as eoEPCs.

As demonstrated in previous studies, EPCs quickly recruit to sites of vascular injury by cytokines and growth factors [35] and stimulate neighbouring EC migration and proliferation by angiogenic growth factor production [36] contributing to endothelial regeneration in injured arteries. In addition, maintenance of normal number and function of circulating EPCs has 
A

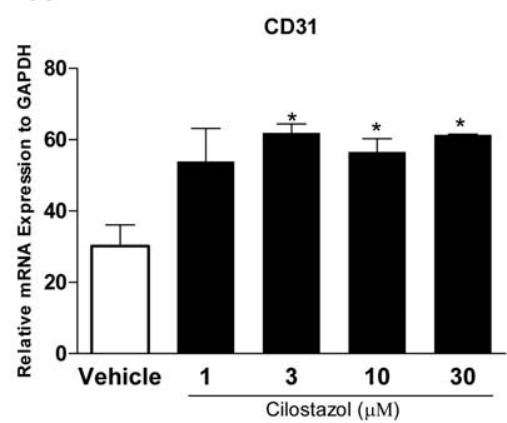

C

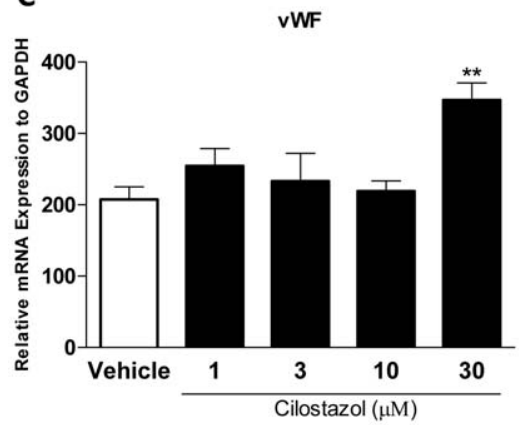

B

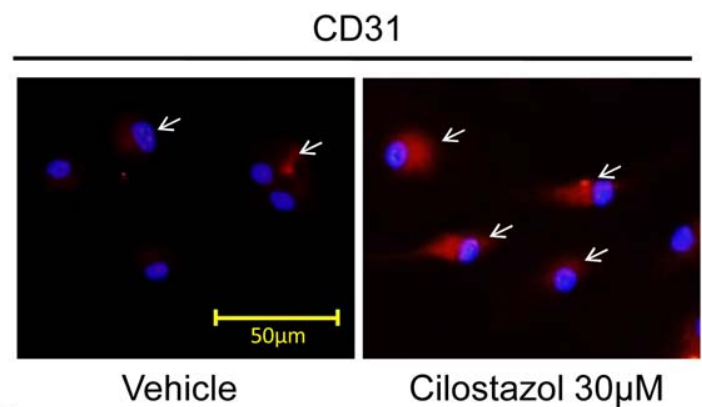

D

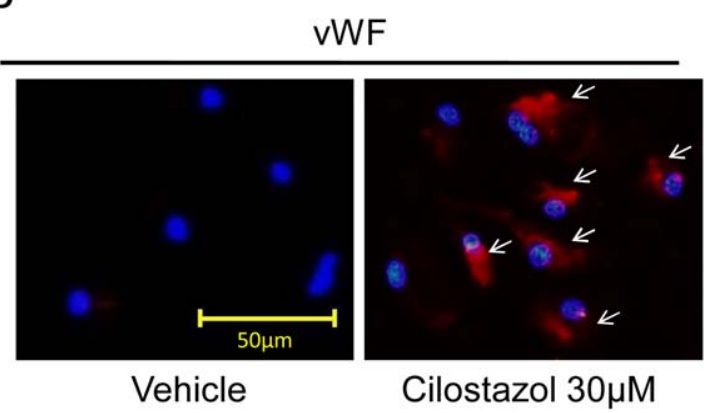

Figure 6. Cilostazol promotes EPC differentiation to endothelial lineage. Cultured EPCs were treated with Cilostazol at the indicated concentrations for $3 \mathrm{~h}$ and cultured for an additional 48 hours in EPC differentiation medium. Differentiation activity was examined by real-time RTPCR analyses for CD31 (A) and vWF (C) mRNA expressions as endothelial markers. ${ }^{*} P<0.05$ and ${ }^{* *} P<0.01$ vs. Vehicle. Representative immunofluorescence photomicrographs for CD31 (B) and VWF (D) in cultured EPCs treated with Cilostazol. Arrows indicate CD31- and vWFpositive cells. All experiments were performed in triplicate and confirmed the reproducibility. doi:10.1371/journal.pone.0024646.g006

A

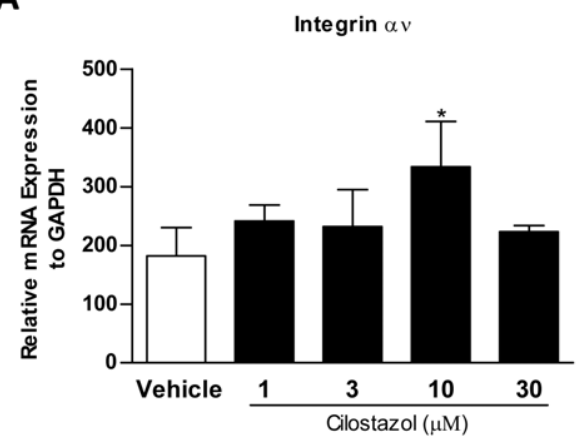

C

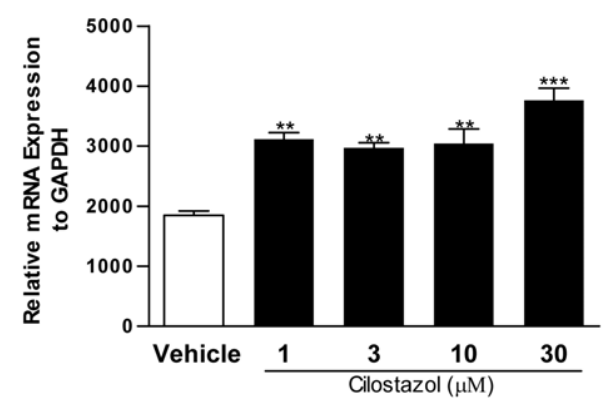

B

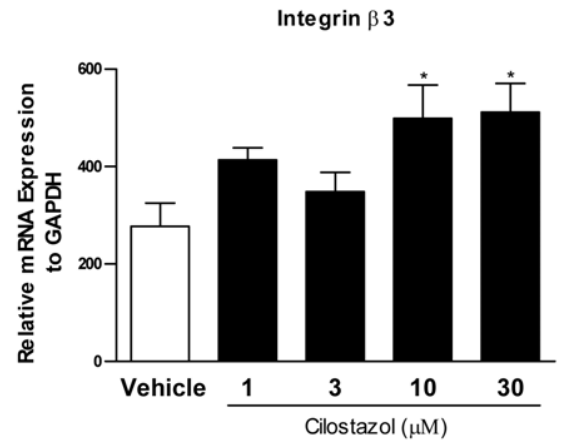

D

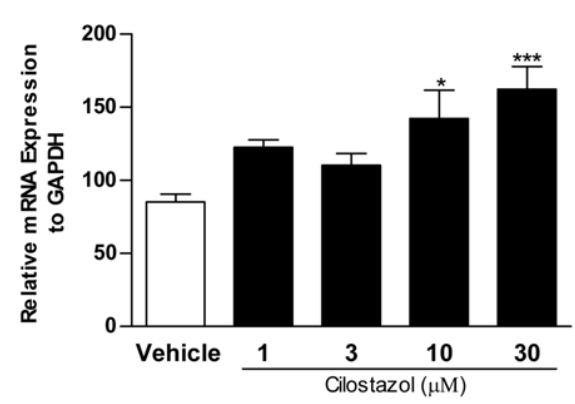

Figure 7. Cilostazol alters gene expression profile in cultured EPCs. Cultured EPCs were treated with Cilostazol at the indicated concentrations for $3 \mathrm{~h}$, and total RNA was extracted. The expressions of adhesion molecule integrin $\alpha \mathrm{v}(\mathrm{A}) /$ integrin $\beta 3$ (B), chemokine receptor CXCR4 (C) and growth factor VEGF (D) were examined by quantitative real-time RT-PCR analysis. ${ }^{*}, P<0.05, * *, P<0.01$ and ${ }^{* * *} P<0.001$ vs. Vehicle. All experiments were performed in triplicate and confirmed the reproducibility.

doi:10.1371/journal.pone.0024646.g007 
A

SDF-1

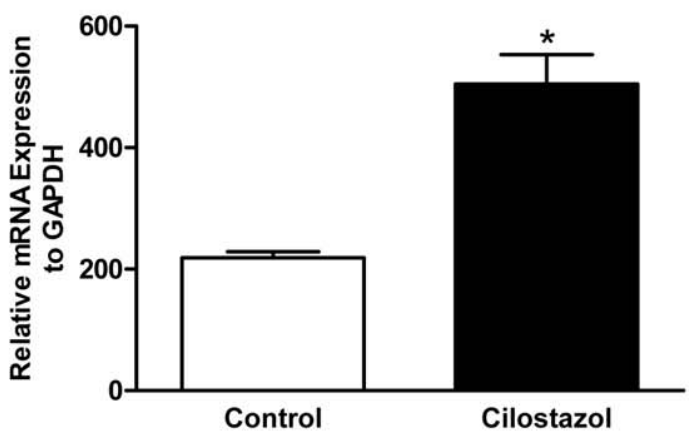

B
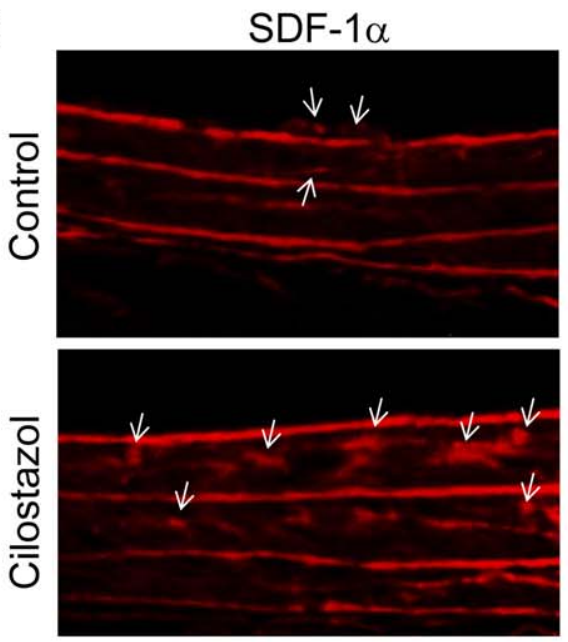

SM $\alpha$-actin
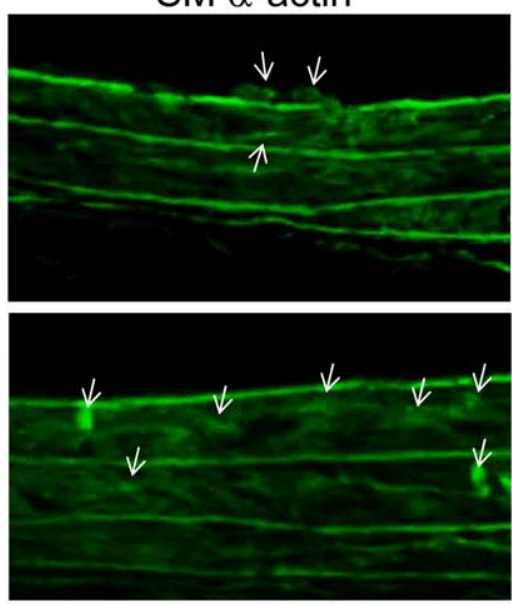

Merged
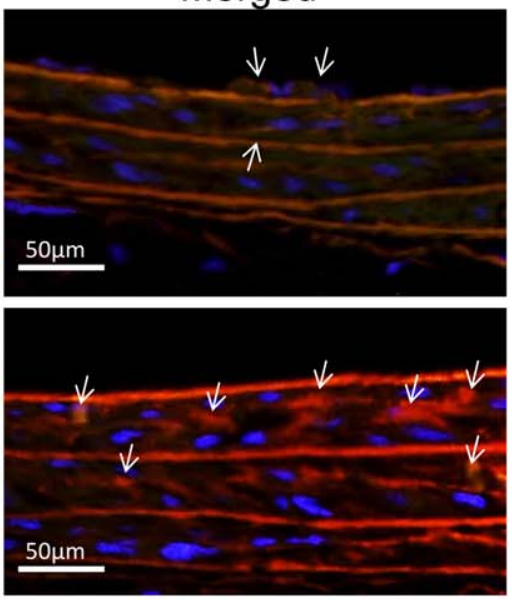

Figure 8. Cilostazol enhances SDF-1 expression in injured carotid artery. Rats were fed with Cilostazol containing diet (Cilostazol group) or normal diet (control group) from 2 weeks prior to carotid injury until time of sacrifice, and inured arteries were examined at 7 days after surgery. (A) The expressions of SDF-1 mRNA were examined by quantitative real-time RT-PCR analysis. ${ }^{*}, P<0.001$ vs. Control. (B) Representative photomicrographs of double-immunofluorescent staining for SDF- $1 \alpha$ shown in red and SM $\alpha$-actin shown in green on histological cross sections in Cilostazol group $(n=4)$ vs. Control group $(n=3)$. Arrows indicate double-positive cells for SDF-1 $\alpha$ and SM $\alpha$-actin.

doi:10.1371/journal.pone.0024646.g008

been reported to be an important novel endogenous vascular repair factor $[37,38,39]$. Therefore, recent studies have proposed that increase of circulating EPC number and activation of EPC function are unique strategies to enhance EPC-mediated reendothelialization. The evidence of CLZ-induced EPC mobilization and homing to sites of injured artery for re-endothelialization that we have demonstrated in this study may give rise to a novel therapeutic strategy for vascular remodeling following vascular intervention as an EPC mobilizer/activator. Our study has also indicated that CLZ enhanced EPC functional properties of adhesion, proliferation, and migration exhibiting the following possible mechanistic insight in the pathophysiological role of EPCs in re-endothelialization.

Vitronectin, an extracellular matrix protein, has been shown to influence cellular migration and differentiation [40,41,42], and Dufourcq et al. showed that VN expression was upreglated in injured rat carotid artery [43]. Our in vitro data of integrin $\alpha v \beta 3$ mRNA upregulation by CLZ treatment in EPCs can therefore explain the enhanced EPC adhesion activity against VN and EPC recruitment to injured vascular wall. Moreover, since interaction of integrin $\alpha_{v} \beta 3$ and $\mathrm{VN}$ is important for cell differentiation [42], upregulation of integrin $\alpha \mathrm{v} \beta 3$ in EPCs is also helpful for EPC differentiation to EC lineage following the attachment on deendothelialized vascular wall. On the other hand, for EPC recruitment to injured vascular wall, a certain chemokine produced from injured artery is also crucial as well as adhesion molecule. Indeed, previous mouse studies have shown that SDF$1 \alpha$ protein was expressed in injured carotid arteries with a marked mobilization of circulating Sca- $1^{+}$Lineage ${ }^{-}$progenitor cells involving EPGs in peripheral blood resulting in cell homing to sites of re-endothelialization, and neutralization of SDF- $1 \alpha$ caused delayed re-endothelialization in injured arteries [44,45,46,47]. The receptor for chemokine SDF-1 $\alpha$, CXCR4, in EPGs are essential for the homing [45] and CXCR4-blocked EPCs could not recruit to injured arteries [33,48] In contrast, overexpression of CXCR4 by gene transfer improves functional properties of human EPCs and enhances re-endothelialization in injured artery [49]. These evidences clearly show that SDF- $1 \alpha /$ CXCR 4 axis is critical for EPC recruitment to injured vascular wall, and therefore upregulation of both CXCR4 in circulating EPCs and SDF- $1 \alpha$ in injured medial VSMCs by CLZ treatment might synergistically promotes EPC-mediated re-endothelialization and CLZ failed to promote VEGF-induced migration activity of EPCs (Figure 5C) in our study. In addition, since SDF- $1 \alpha$ is a releasing chemokine, SDF- $1 \alpha$ produced from injured medial VSMCs may remotely influence BM and contribute to EPC mobilization from BM into circulation. Indeed, a previous report [48] and our data that timing of EPG mobilization and recruitment to injured arterial 
wall were synchronized at 2 weeks after arterial injury (Figure 3 and 4) could support the above speculation.

CLZ is a clinically available phosphodiesterase 3 (PDE3) inhibitor, increasing cellar levels of cAMP, with anti-platelet and vasodilatatory properties [13] and is approved in the US for treatment of patient with intermittent claudication symptoms related to peripheral arterial disease [13,50]. Although distinct mechanism for the favorable effect of CLZ on angiogenesis has not been shown, one very recent study in which CLZ is shown to enhance neovascularization in hippocampus in a mouse model of transient forebrain ischemia via recruitment of BM-derived EPCs [51] suggest a significant contribution of CLZ-induced EPC mobilization/recruitment to angiogenesis in ischemic tissue. For mechanistic insight, as a previous report demonstrated, CLZ increases NO production by the phosphorylation of eNOS with increased cAMP levels and enhances endothelial tube formation in ECs. [52] Since eNOS phosphorylation in BM, in which endothelial/vascular niche for stem/progenitor cells including EPCs is involved, is also crucial for EPC mobilization [4,53], eNOS phosphorylation could be one of the mechanisms of CLZinduced EPC mobilization. Furthermore, CLZ might induce eNOS phosphorylation in EPCs themselves as well as in ECs resulting in EPC functional activation as Statins did [54]. CLZ has also been shown to reduce post-procedural in-stent restenosis after arterial stenting $[18,19,20]$. DES has dramatically reduced the rate of restenosis; however, DESs also appears to delay re-endothelialization [1]. This delay results in late angiographic in-stent thrombosis leading to such as an acute coronary syndrome. For instance, Sirolimus, one of the coating materials of DES, accelerates senescence and inhibit proliferation and differentiation, migration of EPCs [55,56] and EC dysfunction [57], thereby delayed re-endothelialization [58]. In terms of avoiding adverse side effects of DES, CLZ treatment following arterial stenting with DES could be an useful anti-platelet/coagulation therapy for preventing in-stent thrombosis rather than the other anti-platelet agents i.e aspirin, ticlopidine, IIb/IIIa antagonist, and so forth.

In conclusion. the results in the present study provided novel evidences that CLZ inhibited neointima formation following arterial injury accelerating endothelial regeneration with enhancement of BM-derived EPG mobilization, EPC recruitment to sites of injured vessel wall, and EPG function. CLZ could be a promising agent for not only just anti-platelet medicine but also a tool for vascular regenerative medicine.

\section{References}

1. Liistro F, Colombo A (2001) Late acute thrombosis after paclitaxel eluting stent implantation. Heart 86: 262-264.

2. Asahara T, Isner JM (2002) Endothelial progenitor cells for vascular regeneration. J Hematother Stem Cell Res 11: 171-178.

3. Takahashi T, Kalka C, Masuda H, Chen D, Silver M, et al. (1999) Ischemiaand cytokine-induced mobilization of bone marrow-derived endothelial progenitor cells for neovascularization. Nat Med 5: 434-438.

4. Laufs U, Werner N, Link A, Endres M, Wassmann S, et al. (2004) Physical training increases endothelial progenitor cells, inhibits neointima formation, and enhances angiogenesis. Circulation 109: 220-226.

5. Walter DH, Rittig K, Bahlmann FH, Kirchmair R, Silver M, et al. (2002) Statin therapy accelerates reendothelialization: a novel effect involving mobilization and incorporation of bone marrow-derived endothelial progenitor cells. Circulation 105: 3017-3024.

6. Werner N, Priller J, Laufs U, Endres M, Bohm M, et al. (2002) Bone marrowderived progenitor cells modulate vascular reendothelialization and neointimal formation: effect of 3-hydroxy-3-methylglutaryl coenzyme a reductase inhibition. Arterioscler Thromb Vasc Biol 22: 1567-1572.

7. Iwakura A, Luedemann C, Shastry S, Hanley A, Kearney M, et al. (2003) Estrogen-mediated, endothelial nitric oxide synthase-dependent mobilization of bone marrow-derived endothelial progenitor cells contributes to reendothelialization after arterial injury. Circulation 108: 31153121 .

\section{Materials and Methods}

All procedures and animal care were approved by the Wakayama medical university Institutional Animal Care and Use Committee (Approval Number: 351) and the Ethical Committee in Institute of Biomedical Research and Innovation (IBRI)/RIKEN Center for Developmental Biology (Approval Number: AH21-02), and complied with the Japanese Physiological Society Guidelines for the Care and Use of Laboratory Animals.Cilostazol \{6-[4-(1-cyclohexyl-1H-tetrazol-5-yl)butoxy]-3,4-dihydro-2-(1H)-quinolinone (CLZ) were gifted from Otsuka Pharmaceutical (Tokushima, Japan). The Male Sprague-Dawley (SD) rats (16 to 19 weeks old, 350 to $450 \mathrm{~g}$ ) were divided into two groups. One group was fed a standard rat diet (control group), and the other group was given a $0.2 \%$ CLZ mixed diet (CLZ group) resulting in approximately $60 \sim 80 \mathrm{mg} / \mathrm{kg} /$ day of CLZ intake. Previous study showed $50 \mathrm{mg} / \mathrm{kg} / \mathrm{per}$ day of CLZ intake for 14 days in rat was $1.43 \pm 0.90 \mathrm{mmol} / \mathrm{L}$ of plasma concentration [59],therefore, plasma CLZ level in this study could be equivalent to the dose in human cases [60]. CLZ containing special diet was given 2 weeks before and 2 or 4weeks after carotid injury until they were euthanized. The rats were anesthetized and underwent carotid balloon denudation as described previously [61]. The carotid arteries were examined histologically and blood samples were collected for circulating EPC count before and 2 or 4 weeks after balloon injury. Detailed materials and methods are available in Text $\mathrm{S} 1$ and Table $\mathrm{S} 1$ and Table S2.

\section{Supporting Information}

Text S1 Supplementary Materials and Methods. (DOCX)

Table S1 Antibodies used in Immunocytochemical and Immunohistochemical Analyses.

(DOC)

Table S2 Primers used in Real-time RT-PGR Analysis. (DOC)

\section{Author Contributions}

Conceived and designed the experiments: MI OM TA RK-Y. Performed the experiments: MI RK-Y. Analyzed the data: MI RK-Y. Contributed reagents/materials/analysis tools: MI OM TA TI RK-Y. Wrote the paper: MI TA TI RK-Y.

8. Strehlow K, Werner N, Berweiler J, Link A, Dirnagl U, et al. (2003) Estrogen increases bone marrow-derived endothelial progenitor cell production and diminishes neointima formation. Circulation 107: 3059-3065.

9. Asahara T, Takahashi T, Masuda H, Kalka C, Chen D, et al. (1999) VEGF contributes to postnatal neovascularization by mobilizing bone marrow-derived endothelial progenitor cells. Embo J 18: 3964-3972.

10. Cho HJ, Kim HS, Lee MM, Kim DH, Yang HJ, et al. (2003) Mobilized endothelial progenitor cells by granulocyte-macrophage colony-stimulating factor accelerate reendothelialization and reduce vascular inflammation after intravascular radiation. Circulation 108: 2918-2925.

11. Kong D, Melo LG, Gnecchi M, Zhang L, Mostoslavsky G, et al. (2004) Cytokine-induced mobilization of circulating endothelial progenitor cells enhances repair of injured arteries. Circulation 110: 2039-2046.

12. Kimura Y, Tani T, Kanbe T, Watanabe K (1985) Effect of cilostazol on platelet aggregation and experimental thrombosis. Arzneimittelforschung 35: 1144-1149.

13. Kambayashi J, Liu Y, Sun B, Shakur Y, Yoshitake M, et al. (2003) Cilostazol as a unique antithrombotic agent. Curr Pharm Des 9: 2289-2302.

14. Matsumoto M (2005) Cilostazol in secondary prevention of stroke: impact of the Cilostazol Stroke Prevention Study. Atheroscler Suppl 6: 33-40.

15. Ishizaka N, Taguchi J, Kimura Y, Ikari Y, Aizawa T, et al. (1999) Effects of a single local administration of cilostazol on neointimal formation in ballooninjured rat carotid artery. Atherosclerosis 142: 41-46. 
16. Takahashi S, Oida K, Fujiwara R, Maeda H, Hayashi S, et al. (1992) Effect of cilostazol, a cyclic AMP phosphodiesterase inhibitor, on the proliferation of rat aortic smooth muscle cells in culture. J Cardiovasc Pharmacol 20: 900-906.

17. Tsuchikane E, Fukuhara A, Kobayashi T, Kirino M, Yamasaki K, et al. (1999) Impact of cilostazol on restenosis after percutaneous coronary balloon angioplasty. Circulation 100: 21-26.

18. Douglas JS, Jr., Holmes DR, Jr., Kereiakes DJ, Grines CL, Block E, et al. (2005) Coronary stent restenosis in patients treated with cilostazol. Circulation 112: 2826-2832.

19. Zhang Z, Foster JK, Kolm P, Jurkovitz CT, Parker KM, et al. (2006) Reduced 6month resource use and costs associated with cilostazol in patients after successful coronary stent implantation: results from the Cilostazol for RESTenosis (CREST) trial. Am Heart J 152: 770-776.

20. Takigawa T, Matsumaru Y, Hayakawa M, Nemoto S, Matsumura A (2010) Cilostazol reduces restenosis after carotid artery stenting. J Vasc Surg 51: 51-56.

21. Kim KY, Shin HK, Choi JM, Hong KW (2002) Inhibition of lipopolysaccharide-induced apoptosis by cilostazol in human umbilical vein endothelial cells. J Pharmacol Exp Ther 300: 709-715.

22. Morishita R, Higaki J, Hayashi SI, Yo Y, Aoki M, et al. (1997) Role of hepatocyte growth factor in endothelial regulation: prevention of high Dglucose-induced endothelial cell death by prostaglandins and phosphodiesterase type 3 inhibitor. Diabetologia 40: 1053-1061.

23. Aoki M, Morishita R, Hayashi S, Jo N, Matsumoto K, et al. (2001) Inhibition of neointimal formation after balloon injury by cilostazol, accompanied by improvement of endothelial dysfunction and induction of hepatocyte growth factor in rat diabetes model. Diabetologia 44: 1034-1042.

24. Shin HK, Kim YK, Kim KY, Lee JH, Hong KW (2004) Remnant lipoprotein particles induce apoptosis in endothelial cells by $\mathrm{NAD}(\mathrm{P}) \mathrm{H}$ oxidase-mediated production of superoxide and cytokines via lectin-like oxidized low-density lipoprotein receptor-1 activation: prevention by cilostazol. Circulation 109: $1022-1028$

25. Otsuki M, Saito H, Xu X, Sumitani S, Kouhara H, et al. (2001) Cilostazol represses vascular cell adhesion molecule-1 gene transcription via inhibiting NFkappaB binding to its recognition sequence. Atherosclerosis 158: 121-128.

26. Nishio Y, Kashiwagi A, Takahara N, Hidaka H, Kikkawa R (1997) Cilostazol, a cAMP phosphodiesterase inhibitor, attenuates the production of monocyte chemoattractant protein-1 in response to tumor necrosis factor-alpha in vascular endothelial cells. Horm Metab Res 29: 491-495.

27. Omi H, Okayama N, Shimizu M, Fukutomi T, Nakamura A, et al. (2004) Cilostazol inhibits high glucose-mediated endothelial-neutrophil adhesion by decreasing adhesion molecule expression via NO production. Microvasc Res 68: $119-125$.

28. Zampetaki A, Kirton JP, Xu Q (2008) Vascular repair by endothelial progenitor cells. Cardiovasc Res 78: 413-421.

29. Sanada F, Taniyama Y, Azuma J, Iekushi K, Dosaka N, et al. (2009) Hepatocyte growth factor, but not vascular endothelial growth factor, attenuates angiotensin II-induced endothelial progenitor cell senescence. Hypertension 53: 77-82.

30. Leone AM, Valgimigli M, Giannico MB, Zaccone V, Perfetti M, et al. (2009) From bone marrow to the arterial wall: the ongoing tale of endothelial progenitor cells. Eur Heart J 30: 890-899.

31. Hristov M, Weber C (2004) Endothelial progenitor cells: characterization, pathophysiology, and possible clinical relevance. J Cell Mol Med 8: 498-508.

32. Giannotti G, Doerries C, Mocharla PS, Mueller MF, Bahlmann FH, et al. (2010) Impaired endothelial repair capacity of early endothelial progenitor cells in prehypertension: relation to endothelial dysfunction. Hypertension 55: 1389-1397.

33. Hristov M, Zernecke A, Bidzhekov K, Liehn EA, Shagdarsuren E, et al. (2007) Importance of CXC chemokine receptor 2 in the homing of human peripheral blood endothelial progenitor cells to sites of arterial injury. Circ Res 100: $590-597$.

34. Sorrentino SA, Bahlmann FH, Besler C, Muller M, Schulz S, et al. (2007) Oxidant stress impairs in vivo reendothelialization capacity of endothelial progenitor cells from patients with type 2 diabetes mellitus: restoration by the peroxisome proliferator-activated receptor-gamma agonist rosiglitazone. Circulation 116: 163-173.

35. Dimmeler S, Zeiher AM (2004) Vascular repair by circulating endothelial progenitor cells: the missing link in atherosclerosis? J Mol Med 82: 671-677.

36. Urbich C, Aicher A, Heeschen C, Dernbach E, Hofmann WK, et al. (2005) Soluble factors released by endothelial progenitor cells promote migration of endothelial cells and cardiac resident progenitor cells. J Mol Cell Cardiol 39: 733-742.

37. Asahara T, Murohara T, Sullivan A, Silver M, van der Zee R, et al. (1997) Isolation of putative progenitor endothelial cells for angiogenesis. Science 275: 964-967.
38. Dzau VJ, Gnecchi M, Pachori AS, Morello F, Melo LG (2005) Therapeutic potential of endothelial progenitor cells in cardiovascular diseases. Hypertension 46: 7-18.

39. Lamping K (2007) Endothelial progenitor cells: sowing the seeds for vascular repair. Circ Res 100: 1243-1245.

40. Chavakis E, Aicher A, Heeschen C, Sasaki K, Kaiser R, et al. (2005) Role of beta2-integrins for homing and neovascularization capacity of endothelial progenitor cells. J Exp Med 201: 63-72.

41. Chavakis E, Hain A, Vinci M, Carmona G, Bianchi ME, et al. (2007) Highmobility group box 1 activates integrin-dependent homing of endothelial progenitor cells. Circ Res 100: 204-212.

42. Rahman S, Patel Y, Murray J, Patel KV, Sumathipala R, et al. (2005) Novel hepatocyte growth factor (HGF) binding domains on fibronectin and vitronectin coordinate a distinct and amplified Met-integrin induced signalling pathway in endothelial cells. BMC Cell Biol 6: 8.

43. Dufourcq P, Couffinhal T, Alzieu P, Daret D, Moreau C, et al. (2002) Vitronectin is up-regulated after vascular injury and vitronectin blockade prevents neointima formation. Cardiovasc Res 53: 952-962.

44. Schober A, Knarren S, Lietz M, Lin EA, Weber C (2003) Crucial role of stromal cell-derived factor-lalpha in neointima formation after vascular injury in apolipoprotein E-deficient mice. Circulation 108: 2491-2497.

45. Sainz J, Sata M (2007) CXCR4, a key modulator of vascular progenitor cells. Arterioscler Thromb Vasc Biol 27: 263-265.

46. Karshovska E, Zernecke A, Sevilmis G, Millet A, Hristov M, et al. (2007) Expression of HIF-1alpha in injured arteries controls SDF-lalpha mediated neointima formation in apolipoprotein E deficient mice. Arterioscler Thromb Vasc Biol 27: 2540-2547.

47. Zernecke A, Schober A, Bot I, von Hundelshausen P, Liehn EA, et al. (2005) SDF-lalpha/CXCR4 axis is instrumental in neointimal hyperplasia and recruitment of smooth muscle progenitor cells. Circ Res 96: 784-791.

48. Yin Y, Zhao X, Fang Y, Yu S, Zhao J, et al. (2010) SDF-lalpha involved in mobilization and recruitment of endothelial progenitor cells after arterial injury in mice. Cardiovasc Pathol 19: 218-227.

49. Chen L, Wu F, Xia WH, Zhang YY, Xu SY, et al. (2010) CXCR4 gene transfer contributes to in vivo reendothelialization capacity of endothelial progenitor cells. Cardiovasc Res 88: 462-470.

50. Hiatt WR (2002) Pharmacologic therapy for peripheral arterial disease and claudication. J Vasc Surg 36: 1283-1291.

51. Shin HK, Lee HR, Lee DH, Hong KW, Lee JH, et al. (2010) Cilostazol enhances neovascularization in the mouse hippocampus after transient forebrain ischemia. J Neurosci Res 88: 2228-2238.

52. Hashimoto A, Miyakoda G, Hirose Y, Mori T (2006) Activation of endothelial nitric oxide synthase by cilostazol via a cAMP/protein kinase A- and phosphatidylinositol 3-kinase/Akt-dependent mechanism. Atherosclerosis 189: 350-357.

53. Aicher A, Heeschen C, Mildner-Rihm C, Urbich C, Ihling C, et al. (2003) Essential role of endothelial nitric oxide synthase for mobilization of stem and progenitor cells. Nat Med 9: 1370-1376.

54. Dimmeler S, Aicher A, Vasa M, Mildner-Rihm G, Adler K, et al. (2001) HMGCoA reductase inhibitors (statins) increase endothelial progenitor cells via the PI 3-kinase/Akt pathway. J Clin Invest 108: 391-397.

55. Imanishi T, Kobayashi K, Kuki S, Takahashi C, Akasaka T (2006) Sirolimus accelerates senescence of endothelial progenitor cells through telomerase inactivation. Atherosclerosis 189: 288-296.

56. Zhang P, Huang L, Zhu GX, Cui B, Song MB, et al. (2006) [Sirolimus inhibits the differentiation, proliferation and migration of endothelial progenitor cells in vitro]. Zhonghua Xin Xue Guan Bing Za Zhi 34: 1021-1025.

57. Hofma SH, van der Giessen WJ, van Dalen BM, Lemos PA, McFadden EP, et al. (2006) Indication of long-term endothelial dysfunction after sirolimuseluting stent implantation. Eur Heart J 27: 166-170.

58. Fukuda D, Sata M, Tanaka K, Nagai R (2005) Potent inhibitory effect of sirolimus on circulating vascular progenitor cells. Circulation 111: 926-931.

59. Miyamoto N, Tanaka R, Shimura H, Watanabe T, Mori H, et al. (2010) Phosphodiesterase III inhibition promotes differentiation and survival of oligodendrocyte progenitors and enhances regeneration of ischemic white matter lesions in the adult mammalian brain. J Cereb Blood Flow Metab 30: 299-310.

60. Akiyama H, Kudo S, Odomi M, Shimizu T (1985) High-performance liquid chromatographic procedure for the determination of a new antithrombotic and vasodilating agent, cilostazol, in human plasma. J Chromatogr 338: 456-459.

61. Tsuruta W, Yamamoto T, Suzuki K, Yoshida F, Matsumura A (2007) Simple new method for making a rat carotid artery post-angioplasty stenosis model. Neurol Med Chir (Tokyo) 47: 525-529. 